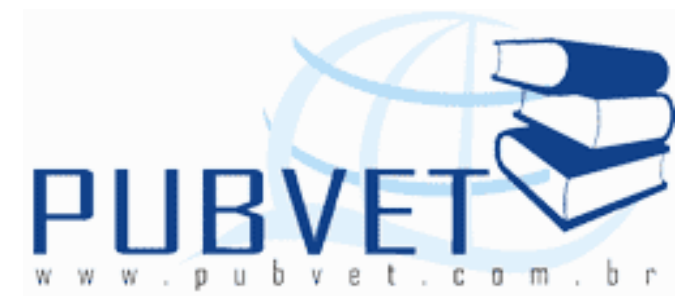

PUBVET, Publicações em Medicina Veterinária e Zootecnia.

\title{
Teores de alguns nutrientes do Rami (Boehmeria nívea CV Myasaki) sob duas fontes de adubo nitrogenado e quatro freqüências de corte
}

Diorande Bianchini ${ }^{1}$, Rosana Aparecida Possenti ${ }^{1}$, Frederico Fontoura Leinz ${ }^{1}$, Ivani Pozar Otsuk ${ }^{1}$, Carlos Frederico de Carvalho Rodrigues ${ }^{1}$, João Elzeário Castelo Branco Iapichini ${ }^{1}$, Luciana Gerdes ${ }^{1}$, Antonio Orlando da Luz Freire Neto $^{2}$

1 Pesquisadores Científicos da Agência Paulista de Tecnologia dos Agronegócios (APTA), Secretaria de Agricultura e Abastecimento do Estado de São Paulo

${ }^{2}$ Pesquisador Científico da Estação Experimental de Itapetininga (IF/SMA).

\section{Resumo}

Esse trabalho foi realizado com o objetivo de avaliar os conteúdos de alguns nutrientes do rami, em quatro freqüências de corte, cada uma das quais adubadas com nitrogênio mineral (sulfato de amônio) ou orgânico (resíduo de limpeza de piso aviário). De maio de 2006 a maio de 2007 foram realizados 13, 10, 08 e 07 cortes nas freqüências 28, 35, 42 e 49 dias, respectivamente. Em cada freqüência, o rami era adubado após cada corte na dosagem de $100 \mathrm{kgN} / \mathrm{ha}$, parcelada pelo número de cortes. Após o corte de uniformização, o solo do rami foi corrigido com calcário dolomítico e adubado com $\mathrm{P}, \mathrm{K}$ e N, e, para melhor incorporação do corretivo, a área foi submetida a um pisoteio animal e irrigada. Determinaram-se a altura da planta e os teores de proteína bruta (PB), fibra bruta (FB), digestibilidade "in 
vitro" da MS (DIVMS), cálcio (Ca) e fósforo (P). Os teores variaram de $12,3 \%$ a $28,3 \%$ em PB; $39,5 \%$ a $79,9 \%$ em DIVMS; $2,0 \%$ a $5,2 \%$ em Ca e $0,26 \%$ a $0,51 \%$ em P. Com exceção ao efeito do IEC na PB, onde houve um decréscimo gradativo linear do IEC de 28 dias para o de 49 dias, em todas as demais variáveis estudadas, seja entre fontes de $\mathrm{N}$ (FN) nos intervalos entre corte (IEC), seja entre os IEC, as diferenças foram praticamente insignificantes. Os teores dos nutrientes estudados foram bastante expressivos, comparáveis e até maiores aos citados para leguminosas como guandu e leucena, cortadas também para alimentação de pequenos ruminantes. Os teores de $\mathrm{Ca}$ foram altos e maiores cuidados devem ser tomados na relação Ca: $\mathrm{P}$ para formulação de rações balanceadas.

Palavras-chave: adubação orgânica, adubação mineral, resíduo de limpeza de piso aviário, sulfato de amônio, nutrição vegetal.

\section{Some nutrient contents of ramie (Boehmeria nívea CV Myasaki) in} four cutting frequencies every one fertilized with mineral or organic

\section{nitrogen}

\section{Abstract}

This work was conducted in the Development Research Unit, ItapetiningaSP, Brazil, in a red darkness latosol Rami (Boehmeria nivea CV Myasaki) was evaluated under two nitrogen sources (mineral: ammonium sulphate; organic: chicken manure) and four cutting frequencies (28, 35, 42 and 49 days). Nitrogen application of each $\mathrm{N}$ source, in the basis of $100 \mathrm{~kg} / \mathrm{ha} /$ year of $N$, was made after each cut. From May 2006 to May 2007, after the uniformity cut 13,10, 8 and 7 cuts were made with 28, 35, 42 and 49 days interval, respectively. Crude protein (CP), crude fiber (CF), "in vitro" digestibility (IVDMD), calcium (Ca) and phosphorus $(P)$ contents were evaluated. The contents varied from $12,3 \%$ to $28,3 \%$ in $\mathrm{CP} ; 39,5 \%$ to $79,9 \%$ in DMIVD; $2,0 \%$ to $5,2 \%$ in $\mathrm{Ca}$ and $0,26 \%$ to $0,51 \%$ in $\mathrm{P}$. There weren't significant differences between nitrogen sources in the studied 
variables. Crude protein content decreased linearly way with increase of cutting interval. There were not significant differences among cutting frequencies in crude fiber, dry matter "in vitro" digestibility, calcium and phosphorus contents. The contents of studied nutrients were plenty significative, reaching values yet larger than quoted by a good quality tree legumes cut also to feed small ruminants. The Ca contents were high and heed must be taken in Ca: $\mathrm{P}$ relation in order to balanced rations formulation.

Keywords: organic fertilizer, mineral fertilizer, manure, ammonium sulphate, vegetal nutrition.

\section{INTRODUÇÃO}

É necessário que a criação de pequenos animais, principalmente de ovinos e caprinos, de importância para a produção de proteína para o homem se desenvolva e acompanhe o crescimento da população consumidora. Mas, para que a atividade atenda ao consumidor, é necessário produzir animais com as características exigidas pelo mercado e com baixo custo de produção. A alimentação é o principal fator que onera a criação de cabritos e cordeiros, sendo a proteína da dieta o nutriente de maior custo. Neste ponto, o rami, planta da família das urticácias, nativa da China, apresenta-se com notável valor como forragem. Pelo alto teor de proteína (semelhante ao de grãos de leguminosas), e riqueza em minerais, sobretudo em cálcio, Duarte, Sgarbieri e Benatti Júnior (1997) consideram o rami como alimento de natureza protéica.

Em razão da aceitabilidade e produção e características nutricionais de forragem, o rami foi utilizado com sucesso na alimentação e produção de leite de cabras Saanen (SANTOS et al., 1990). Estes autores comentam ser tecnicamente viável a utilização do rami na dieta, e, para uma perspectiva de incremento de até $15 \%$ na produção de leite, recomendam-no na proporção de $55 \%$ na MS do volumoso. 
O rami pode ser fornecido recém colhido; murcho (desidratado), $24 \mathrm{~h}$ após o corte; e na forma de feno. No ganho de peso de caprinos, na proporção de $30 \%$ da dieta, o feno de rami foi melhor que o de napier; e, na proporção de 60\%, foi melhor que o de soja (SILVA et al., 1996).

Porém, há necessidade de verificar, em função de diferentes tipos de adubação nitrogenada e intervalos entre cortes, a qualidade do rápido crescimento vegetativo que o rami apresenta em condições favoráveis de umidade e periódica aplicação de nitrogênio.

Teores de PB, FB, digestibilidade, cálcio e fósforo variaram com a altura, idade e cultivar, bem como com o tipo de solo e adubação de cultivo do rami (SQUIBB et al., 1954; MACHIN, 1977; BUFARAH et al., 1986; GHISI et al., 1994).

Quanto a teor de MS na planta de rami, Santos et al. (1995) encontraram teores médios de $13,2 \%$ na parte aérea; Spoladore et al. (1984) obtiveram $25,6 \%$ em folhas mais novas e $26,7 \%$ em folhas mais velhas na variedade Miyasaki, e 30,1\% e 31,5\% na variedade Saikeiseishim da planta em inflorescência. Alves et al. (1997) obtiveram 15,6\% e Oliveira (2007) obteve 18,$0 ; 19,8,20,4$ e $21,8 \%$, respectivamente, nas freqüências de corte de $28,35,42$ e 49 dias em ramizal adubado em dose única com 20 t/ha de adubo orgânico.

Com relação à PB no rami, Alves et al. (1997) obtiveram 14,9\% em rami cortado a cada 28 dias; trabalho de revisão sobre o rami como alimento animal consta teor variando de 11,1 a 22,7\% (MACHIN, 1977). Ghisi et al. (1994) encontraram 17,0\% para a planta cortada a cada 35 dias, e $14,6 \%$ a cada 49 dias; para plantas cortadas a cada 30 dias no período de agosto a novembro, Bufarah et al. (1986) obtiveram 16,3\%, e em folhas novas e velhas das variedades Saikeiseishim e Miyasaki em inflorescência, Spoladore et al. (1984) encontraram $24,6 \%$ e $17,2 \%$, e $19,2 \%$ e 17,4\%, respectivamente, para intervalos de corte inferiores a 50-60 dias. Echeverry (1960) citou faixa de 25,0 a 18,0\%; Squibb et al. (1954) obtiveram variação de 28,1 a $14,1 \%$ em ramizal adubado com 16 t/ha de piso aviário e cortado 

sob duas fontes de adubo nitrogenado e quatro freqüências de corte. PUBVET, Londrina, V. 6, N. 13, Ed. 200, Art. 1341, 2012.

na altura de 12 a $84 \mathrm{~cm}$; Medina (1963) e Rodriguez et al. (1996) citaram $24,0 \%$ para folhas desta urticácea. Oliveira (2007) obteve 19,$5 ; 19,0 ; 17,8$ e 16,0 \%, respectivamente, nas freqüências de corte de 28, 35, 42 e 49 dias em ramizal adubado em dose única com 20 t/ha de adubo orgânico. Duarte, Sgarbieri e Benatti Júnior (1997) obtiveram 21,0\%. Com relação à planta forrageira, Primavesi (1982) e Werner (1984) associaram menos proteínas com o avanço de idade da mesma.

No que se refere à FB, em revisão do rami como alimento animal, Machin (1977) citou faixa de variação de $11,3 \%$ a $29,0 \%$; em folhas novas e velhas de rami em inflorescência, Spoladore et al. (1984) obtiveram 11,9\% e $13,7 \%$ na variedade Saikeiseishim, e $14,4 \%$ e $11,8 \%$ na variedade Miyasaki. Em plantas de rami de 12,0 a $84,0 \mathrm{~cm}$ de altura, Squibb et al. (1954) encontraram de $9,7 \%$ a 20,8\%. Em intervalos entre cortes de 35 dias e 49 dias, Ghisi et al. (1994) obtiveram 21,9\% e 28,0\%, respectivamente.

Quanto à DIVMS, Schneider e Lucas (1951) observaram que o coeficiente de digestibilidade de uma planta varia de acordo com a idade e a composição no momento da colheita. Alves et al. (1997) obtiveram coeficientes de $62,6 \%$ a $57,4 \%$ em intervalos entre cortes de 28 a 84 dias. Para os intervalos entre cortes de 35 dias e 49 dias, Ghisi et al. (1994) encontraram 56,4\% e 54,2\%. Em intervalos entre cortes de 30 dias, realizados de agosto a novembro, Bufarah et al. (1986) obtiveram 46,5\%; e para rami cortado à idade inferior a 50-60 dias. Echeverry (1960) citou coeficientes de 83,0 a $85,0 \%$.

Com relação a Ca e P, para freqüências de corte de 35 e 49 dias, com 53 e $89 \mathrm{~cm}$ de altura, Ghisi et al. (1994) obtiveram 3,15\% e 3,06\% e 0,24\% e $0,23 \%$, respectivamente. Em revisão do rami como alimento animal, Machin (1977) citou variações de 2,57-4,90\% para o Ca e de 0,14-0,41\% para o P. Em rami adubado com 16 t/ha de piso aviário e submetido a cortes de 12-84 cm de altura, Squibb et al. (1954) obtiveram variações de 4,3-3,3\% para o Ca e 0,57-0,17\% para o P. Duarte, Sgarbieri e Benatti 
Júnior (1997) obtiveram 5,74\% de $\mathrm{Ca}$ e $0,16 \%$ de $\mathrm{P}$ em folhas do rami. Primavesi (1982) associou decréscimo de $\mathrm{P}$ com o avanço de idade da planta.

A demanda crescente por alimentos e bio-combustíveis, e o elevado consumo energético de combustíveis fósseis derivados de petróleo constituem fatores que motivam a busca por fontes alternativas de $\mathrm{N}$ mais acessíveis economicamente para produção animal.

Olivo et al. (1987) não constataram diferenças estatísticas significativas entre fertilizante mineral e cama de bovinos nos teores de PB da forragem e na produção de leite em uma consorciação de aveia com azevém.

A incorporação anual de estrume de curral ou de cama de aviário aumentou significativamente as produções de milho, capim elefante e sorgo (FARIAS et al., 1981).

Em virtude de sua proibição na alimentação animal, a cama de frango pode ser uma das alternativas para uso como fonte de $\mathrm{N}$ para forrageira. Assim, o presente trabalho objetivou avaliar algumas características nutricionais do rami cultivado com fertilização mineral (sulfato de amônio) e com fertilização orgânica (resíduo de limpeza de piso aviário) sob quatro freqüências de corte.

\section{MATERIAL E MÉTODOS}

O trabalho foi conduzido na Unidade de Pesquisas e Desenvolvimento de Itapetininga, da APTA/SAA (Agência Paulista de Tecnologia / Secretaria de Agricultura do Estado de São Paulo), no município de Itapetininga

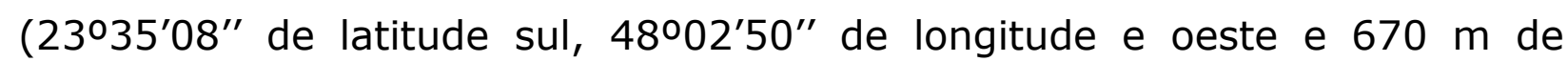
altitude média), no período compreendido entre maio de 2006 e maio de 2007. 
BIANCHINI, D. et al. Teores de alguns nutrientes do Rami (Boehmeria nívea CV Myasaki) sob duas fontes de adubo nitrogenado e quatro freqüências de corte. PUBVET, Londrina, V. 6, N. 13, Ed. 200, Art. 1341, 2012.

Algumas características climáticas do período experimental encontram-se no Quadro I.

Quadro I: Precipitações pluviométricas e temperaturas máximas e mínimas mensais mensuradas durante o período experimental no município de Itapetininga-SP.

\begin{tabular}{|c|c|c|c|}
\hline $\begin{array}{c}\text { Mês/ano } \\
-\end{array}$ & $\begin{array}{c}\text { Precipitação } \\
\text { pluviométrica } \\
\mathrm{mm}\end{array}$ & $\begin{array}{c}\text { Temperatura } \\
\text { mínina } \\
{ }^{\circ} \mathrm{C}\end{array}$ & $\begin{array}{c}\text { Temperatura } \\
\text { máxima } \\
{ }^{\circ} \mathrm{C}\end{array}$ \\
\hline Mai/2006 & 16,5 & 22,7 & 12,3 \\
\hline Jun/2006 & 30,0 & 22,8 & 12,8 \\
\hline Jul/2006 & 91,1 & 23,4 & 12,4 \\
\hline Ag/2006 & 16,3 & 23,9 & 13,4 \\
\hline Set/2006 & 88,7 & 25,7 & 14,4 \\
\hline Out/2006 & 85,1 & 26,6 & 16,7 \\
\hline Nov/2006 & 98,9 & 29,5 & 17,6 \\
\hline Dez/2006 & 235,0 & 30,8 & 20,5 \\
\hline Jan/2007 & 362,3 & 29,3 & 20,3 \\
\hline Fev/2007 & 92,2 & 30,9 & 20,0 \\
\hline Mar/2007 & 63,9 & 31,7 & 20,8 \\
\hline Abr/2007 & 53,1 & 29,0 & 19,8 \\
\hline Mai/2007 & 64,6 & 22,9 & 13,3 \\
\hline
\end{tabular}

O solo do local é classificado como Latossolo Vermelho - Escuro Orto, com a seguinte composição química: M.O. $=46 \mathrm{~g} / \mathrm{kg} ; \mathrm{pH}=4,5 ; \mathrm{P}=13,0$ $\mathrm{mg} / \mathrm{dm}^{3} ; \mathrm{K}^{+}=6,3 \mathrm{mg} / \mathrm{dm}^{3} ; \mathrm{Ca}^{2+}=23,0 \mathrm{mmol} / \mathrm{dm}^{3} ; \mathrm{Mg}^{2+}=11,0$ $\mathrm{mmol} / \mathrm{dm}^{3} ; \mathrm{H}^{+}+\mathrm{Al}^{3+}=50,0 \mathrm{mmol} / \mathrm{dm}^{3} ; \mathrm{CTC}=90,3 \mathrm{mmol} / \mathrm{dm}^{3}$ e $\mathrm{V}=$ $44,6 \%$.

A gleba experimental foi delimitada em área de cultivo de rami préexistente, em 17/5/06, quando as plantas apresentavam altura média de $1,0 \mathrm{~m}$. Aplicaram-se 2,67 t/ha de calcário dolomítico conforme recomendado 
por Werner (1984). Em seguida, a gleba foi irrigada por aspersão para promover melhor incorporação do corretivo.

Uma semana depois, em 24/5/06, realizou-se corte rente ao solo para uniformizar a cultura a $5,0 \mathrm{~cm}$ de altura do solo. Todo o material cortado foi removido da área experimental e, posteriormente, foram aplicados fertilizantes em doses correspondentes a $40 \mathrm{~kg} / \mathrm{ha}$ de $\mathrm{P}_{2} \mathrm{O}_{5}$ e $24 \mathrm{~kg} / \mathrm{ha}$ de $\mathrm{K}_{2} \mathrm{O}$, bem como frações das fontes (mineral e orgânica) de $\mathrm{N}$, definidas em função dos tratamentos e freqüências de corte. Considerou-se esta data para fins de contagem do tempo para aplicação da observação das freqüências de corte.

Avaliaram-se os efeitos de oito tratamentos obtidos pela combinação de duas fontes de $\mathrm{N}$, alocadas nas parcelas, e quatro intervalos entre cortes, alocados nas subparcelas. As subparcelas experimentais tiveram dimensões $3,0 \times 2,5 \mathrm{~m}\left(7,5 \mathrm{~m}^{2}\right)$, com $1,5 \times 2,0 \mathrm{~m}\left(3,0 \mathrm{~m}^{2}\right)$ de área útil. O delineamento experimental utilizado foi o de blocos ao acaso, com três repetições.

As fontes de $\mathrm{N}$ foram o fertilizante sulfato de amônio (20 dag $/ \mathrm{kg}$ de $\mathrm{N}-\mathrm{NH}_{4}{ }^{+}$) como fonte mineral (FM), e o resíduo de cama de galinhas de postura $(1,78 \mathrm{dag} / \mathrm{kg}$ de $\mathrm{N}$ total) como fonte orgânica (FO). Estas foram aplicadas nas doses de $500 \mathrm{~kg} / \mathrm{ha} / \mathrm{ano}$ e $6.800 \mathrm{~kg} / \mathrm{ha} / \mathrm{ano}$, respectivamente, de forma a fornecer a dose total de $100 \mathrm{~kg} / \mathrm{ha}$ de $\mathrm{N}$. As freqüências de cortes corresponderam a 28, 35, 42 e 49 duas entre dois cortes sucessivos, obtidos por meio da realização de 13, 10, 08 e 07 cortes durante o ano, respectivamente.

As fontes de $\mathrm{N}$ foram aplicadas após a realização de cada corte, em 13, 10, 08 e 07 parcelas iguais, definidas em função do número de cortes adotado para o referido tratamento. Juntamente com o $\mathrm{N}$ parcelado, foi feita a reposição de cloreto de potássio, de acordo com a quantidade de forragem removida no corte anterior (WERNER, 1984).

Os cortes foram realizados a 5,0 cm de altura do solo com auxilio de ferramenta manual e as partes colhidas foram ficadas e homogeneizadas. 
Amostras de 400 gramas foram coletadas e postas a secar em estufa com circulação forçada de ar a $65^{\circ} \mathrm{C}$.

Posteriormente as amostras foram moídas e encaminhadas ao Laboratório de Bromatologia e Minerais do Instituto de Zootecnia (APTA/SAA) para as determinações de matéria seca total a 100\% (MS), proteína bruta (PB), fibra bruta (FB), digestibilidade in vitro da matéria seca (DIVMS), matéria seca digestível (MS digestível) e dos minerais cálcio (Ca) e fósforo $(P)$.

A matéria seca foi obtida pelo resíduo de secagem da amostra em estufa a $103-105^{\circ} \mathrm{C}$; a $\mathrm{PB}$, pelo método de Kjeldahl (micro); a $\mathrm{FB}$, pelo método por hidrólise ácida e alcalina; a DIVMS, pelo método de dois estágios Tilley e Terry (1963); e o Ca e o P, por digestão nitro/perclórica.

Determinados através de amostras compostas, os resultados impossibilitaram a realização de análises estatísticas, com exceção ao teor de matéria seca.

\section{RESULTADOS E DISCUSSÃO}

Os resultados referentes a teores de matéria pré-seca (MS a $65^{\circ} \mathrm{C}$ ) e de matéria seca (MS) do rami, nos IEC e fontes de nitrogênio, podem ser vistos na Tabela I.

Os teores de MS a $65^{\circ} \mathrm{C}$ na planta adubada com $\mathrm{N}$ orgânico foram praticamente iguais aos da planta adubada com $\mathrm{N}$ mineral, mas nas freqüências de corte houve um ligeiro aumento linear do IEC de 28 dias para o de 49 dias.

Para o teor de MS, não houve diferença $(P>0,05)$ entre as duas fontes de $\mathrm{N}$ e entre a interação de $\mathrm{N}$ e IEC, havendo diferença $(P>0,05)$ somente para o efeito de IEC, os quais se ajustaram a equações de regressão, mostrando uma resposta linear positiva conforme mostra a Figura I. 
BIANCHINI, D. et al. Teores de alguns nutrientes do Rami (Boehmeria nívea CV Myasaki) sob duas fontes de adubo nitrogenado e quatro freqüências de corte. PUBVET, Londrina, V. 6, N. 13, Ed. 200, Art. 1341, 2012.

Tabela I - Médias de teores de matéria pré-seca (MS a $65^{\circ} \mathrm{C}$ ) e de matéria seca (MS) do rami, nas freqüências de corte (IEC) de 28, 35, 42 e 49 dias, e duas fontes de nitrogênio, mineral (FM) e orgânica (FO).

\begin{tabular}{|c|c|c|c|c|c|c|}
\hline IEC & \multicolumn{3}{|c|}{$\mathrm{MS}$ a $65^{\circ} \mathrm{C}$} & \multicolumn{3}{|c|}{ MS } \\
\hline Dias & \multicolumn{6}{|c|}{$\%$} \\
\hline - & FM & FO & Média & FM & FO & Média \\
\hline 28 & 15,0 & 15,0 & 15,0 & 13,8 & 13,8 & 13,8 \\
\hline 35 & 16,1 & 15,7 & 15,9 & 14,9 & 14,5 & 14,7 \\
\hline 42 & 16,8 & 16,9 & 16,9 & 15,5 & 15,5 & 15,5 \\
\hline 49 & 17,3 & 17,2 & 17,3 & 16,1 & 16,0 & 16,1 \\
\hline Média & 16,3 & 16,2 & - & 15,1 & 15,0 & - \\
\hline CV(a)\% & \multicolumn{3}{|c|}{ - } & \multicolumn{3}{|c|}{1,20} \\
\hline$C V(b) \%$ & \multicolumn{3}{|c|}{ - } & \multicolumn{3}{|c|}{2,84} \\
\hline
\end{tabular}

$$
Y=10,88+0,1074 X \quad R 2=0,98
$$

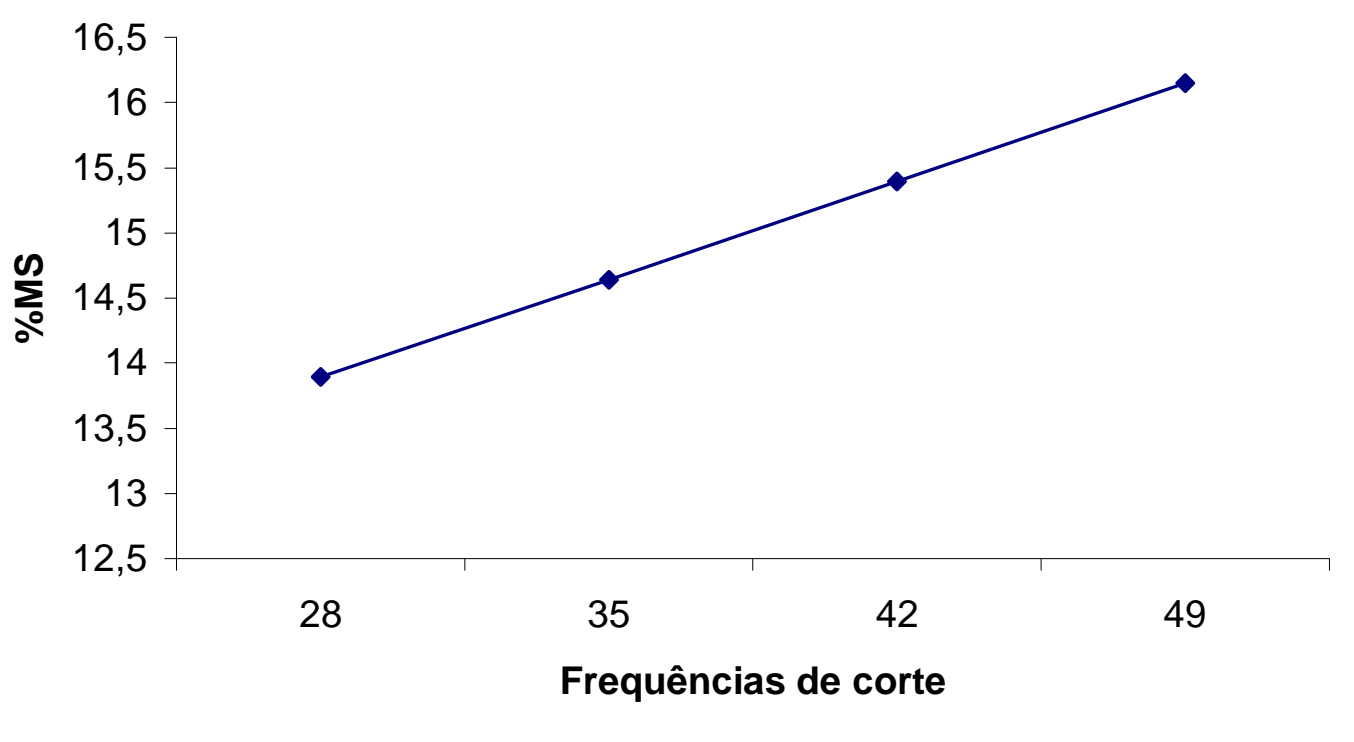

Figura I - Efeito do IEC no teor de MS do rami. 

sob duas fontes de adubo nitrogenado e quatro freqüências de corte. PUBVET, Londrina, V. 6, N. 13, Ed. 200, Art. 1341, 2012.

Houve um incremento linear no teor de MS com o aumento do IEC.

Os teores de MS, cujos resultados no presente trabalho provêm de análises de amostras contendo da planta inteira de rami (caule, folhas e ponteiros), foram maiores que o obtido por Santos et al. (1995) na parte aérea da planta; menores que os obtidos por (SPOLADORE et al.,1984) em folhas novas e velhas das variedades Saikeiseishim e Miyasaki em inflorescência, Alves et al. (1997) em iguais freqüências de corte (28 e 42 dias), Oliveira (2007) nas freqüências de corte de 28, 35, 42 e 49 dias, não obstante tenha, este último, adubado em dose única a cultura com 20 t/ha de adubo orgânico, e nestas circunstâncias esperaria uma cultura com relação folha/caule maior, e menor teor de matéria seca.

As diferenças, entre o presente trabalho e a literatura consultada, nos teores dos nutrientes avaliados, podem ser atribuídas à composição de amostra, idade de componentes, condições de clima e solo, cultivar, etc.. Amostra contendo apenas a parte aérea da planta apresenta mais água, e, assim, Santos et al. (1995) encontraram menor teor de MS.

Em cultura irrigada há uma maior liberação de elementos químicos, sobretudo de $\mathrm{N}$, e, em função disso, as irrigações estratégicas, realizadas em alguns veranicos ocorridos durante o ano, devem ter beneficiado a cultura de rami do presente, aumentando a vigor e o teor de água das plantas, e diminuindo o teor de MS em relação aos resultados obtidos por Spoladore et al. (1984), Alves et al. (1997) e Oliveira (2007), embora, neste caso, as condições edafoclimáticas, de maneira menos significativa, também possam ter influenciado.

Os resultados referentes a teores de proteína bruta (PB) e fibra bruta nos IEC e fontes de nitrogênio podem ser vistos na tabela II.

Os teores de PB na planta adubada com $\mathrm{N}$ mineral foram semelhantes aos da planta adubada com N orgânico. Olivo et al. (1987), também, observaram, em pastagem de azevém consorciada com aveia adubada com fertilizante mineral, semelhantes teor de PB na forragem e produção de leite quando comparados aos do referido ecossistema adubado com cama de 
bovinos; e Farias et al. (1981) observaram aumentos significativos nas produções de milho, capim elefante e sorgo incorporando anualmente em tais culturas tanto estrume de curral como de cama de aviário.

Tabela II - Teores médios de FB e PB no rami, no período experimental de um ano, em quatro IEC (28, 35, 42 e 49 dias) e duas fontes de nitrogênio, mineral (FM) e orgânica (FO).

\begin{tabular}{|c|c|c|c|c|c|c|}
\hline IEC & \multicolumn{4}{|c|}{ PB } & \multicolumn{3}{c|}{ FB } \\
\hline Dias & \multicolumn{3}{|c|}{ FO } & Média \\
\hline- & FM & FO & Média & FM & FO & 17,0 \\
\hline 28 & 23,4 & 23,0 & 23,2 & 17,1 & 16,9 & 20,7 \\
\hline 35 & 20,8 & 20,1 & 20,4 & 21,0 & 20,4 & 24,9 \\
\hline 42 & 18,5 & 17,6 & 18,1 & 25,6 & 24,1 & 24,8 \\
\hline 49 & 17,1 & 17,4 & 17,2 & 26,0 & 23,6 & - \\
\hline Média & 19,9 & 19,5 & - & 22,4 & 21,3 & \\
\hline
\end{tabular}

Os teores de PB diminuíram ligeiramente do IEC de 28 dias para o de 49 dias, corroborando com Werner (1984) e Primavesi (1982) que associaram menos proteínas com o avanço da idade da planta forrageira.

A faixa de variação de teores de PB foi semelhante à de Echeverri (1960) em plantas cortadas antes de 50 a 60 dias de idade, e com a de Spoladore et al. (1984) em folhas novas e velhas da variedade Saikeiseishim em inflorescência; não atingiram o maior valor faixa de variação citada por Squibb et al. (1954), mas superaram significativamente o menor valor da referida faixa, cujos resultados foram obtidos em plantas adubadas com 16 t/ha de piso aviário e cortadas entre 12 e $84 \mathrm{~cm}$ de altura; foram maiores que os obtidos por Oliveira (2007) em folhas nas mesmas freqüências de cortes e variedade adubada com 20 t/ha de fertilizante, por Alves et al. (1997) em planta cortada a cada 28 dias, por GHISI et al. (1994) em 
plantas cortadas a cada 35 e 49 dias, e por Bufarah et al. (1986) em plantas cortadas a cada 30 dias no período de agosto a novembro.

Os teores de PB foram, ainda, no IEC de 28 dias, semelhante aos citados por Medina (1963) e Rodriguez et al. (1996) para folha, e por Spoladore et al. (1984) para folhas novas da variedade Saikeiseishim em inflorescência, e maior que o obtido por Spoladore et al. (1984) em folhas novas e velhas da variedade Myasaki em inflorescência; nos IEC de 28 e 35 dias, semelhantes ao valor máximo da faixa de variação citada por MACHIN (1977); no IEC de 35 dias, semelhante ao obtido por Duarte, Sgarbieri e Benatti Júnior (1997) em folhas; nos IEC de 42 e 49 dias significativamente maiores que o valor mínimo da faixa citada por Machin (1977); e no IEC de 49 dias, semelhante ao obtido por SPOLADORE et al. (1984) em folhas velhas da variedade Saikeiseishim em inflorescência.

Quanto à FB, o teor médio foi levemente menor na planta adubada com $\mathrm{N}$ orgânico que na planta adubada com $\mathrm{N}$ mineral; e teve um aumento do IEC de 28 dias para o de 42 dias, cujos valores situaram-se à média da faixa de variação citada por Machin (1977), tendo sido maiores que os obtidos em folhas novas e velhas das variedades Saikeiseishim e Miyasaki em inflorescência (SPOLADORE et al., 1984).

Nos IEC de 28 e 35 dias, com alturas médias de plantas nas parcelas de 34 e $47 \mathrm{~cm}$, os teores de FB se enquadraram faixa de variação para plantas citada por SQUIBB et al. (1954), mas nos IEC de 42 e 49 dias, com alturas médias de plantas nas parcelas de 63 e $78 \mathrm{~cm}$, os teores de FB foram maiores que o da referida faixa. Em iguais freqüências de corte, Ghisi et al. (1994) obtiveram semelhante teor de FB no IEC de 35 dias e maior teor no IEC de 49 dias.

Os resultados referentes a alturas de plantas e digestibilidade "in vitro" na matéria seca (DIVMS), nas diversas freqüências de corte e fontes de nitrogênio, podem ser vistos na Tabela III. 
Tabela III - Médias de altura de plantas (A) e de digestibilidade "in vitro" na MS (DIVMS) do rami em quatro IEC (28, 35, 42 e 49 dias) e duas fontes de nitrogênio, mineral (FM) e orgânica (FO), no período experimental de um ano.

\begin{tabular}{|c|c|c|c|c|c|c|}
\hline IEC & \multicolumn{3}{|c|}{ Altura de plantas } & \multicolumn{3}{c|}{ DIVMS } \\
\hline Dias & \multicolumn{3}{|c|}{ Cm } & \multicolumn{3}{c|}{$\%$} \\
\hline- & FM & FO & Média & FM & FO & Média \\
\hline 28 & 32 & 35 & 34 & 60,7 & 61,0 & 60,8 \\
\hline 35 & 47 & 46 & 47 & 66,1 & 67,9 & 67,0 \\
\hline 42 & 64 & 62 & 63 & 66,0 & 61,4 & 63,7 \\
\hline 49 & 77 & 78 & 78 & 64,2 & 62,5 & 63,4 \\
\hline Média & 55 & 55 & - & 64,3 & 63,2 & - \\
\hline
\end{tabular}

$\mathrm{Na}$ fonte de $\mathrm{N}$, O $\mathrm{N}$ mineral proporcionou altura de plantas e DIVMS semelhantes ao N orgânico; e na freqüência de cortes houve um aumento na altura de plantas do IEC de 28 dias para o de 49 dias, ficando, porém, os valores de DIVMS praticamente inalterados.

A diferença de idades das plantas nos cortes estudados pode não ter sido suficiente para que houvesse alteração na DIVMS do rami; e mesmo o maior IEC pode não ter atingido a idade de corte segundo o que a digestibilidade iniciasse seu decréscimo (SCHNEIDER e LUCAS, 1951).

Os coeficientes de DIVMS no presente trabalho aproximaram-se ao valor mais alto da faixa de variação em cortes de 28 a 84 dias obtida por Alves et al. (1997); foram maiores que os obtidos por Ghisi et al. (1994) nos intervalos de corte de 35 e 49 dias, e por Bufarah et al. (1986) na freqüência de cortes de 30 dias realizada no período de agosto a novembro; e foram menores que os obtidos por Echeverri (1960) em rami cortados a 50 a 60 dias.

Os resultados referentes a alturas de plantas e teores de cálcio e fósforo do rami, nas diversas freqüências de corte e fontes de nitrogênio, encontram-se na Tabela IV. 
Tabela IV - Altura de plantas (A) e teores de Ca e P do rami em quatro IEC $(28,35,42$ e 49 dias) e duas fontes de nitrogênio, mineral (FM) e orgânica (FO), no período experimental de um ano.

\begin{tabular}{|c|c|c|c|c|c|c|}
\hline IEC & \multicolumn{5}{|c|}{ Ca } & \multicolumn{3}{c|}{ P } \\
\hline Dias & \multicolumn{3}{|c|}{ FO dia } & FM & FO & Média \\
\hline- & FM & FO & Méd & & & \\
\hline 28 & 3,59 & 3,60 & 3,60 & 0,40 & 0,43 & 0,42 \\
\hline 35 & 3,12 & 3,56 & 3,34 & 0,35 & 0,39 & 0,37 \\
\hline 42 & 2,81 & 3,01 & 2,91 & 0,33 & 0,35 & 0,34 \\
\hline 49 & 2,71 & 2,89 & 2,80 & 0,29 & 0,36 & 0,33 \\
\hline Média & 3,06 & 3,27 & - & 0,34 & 0,38 & - \\
\hline
\end{tabular}

Os conteúdos de Ca e $\mathrm{P}$ na adubação do rami com $\mathrm{N}$ orgânico foram semelhantes aos da adubação com $\mathrm{N}$ mineral; e tiveram pequena queda do IEC de 28 dias para o de 49 dias. Primavesi (1982) também citou decréscimo de $\mathrm{P}$ com o avanço da idade da planta.

Os teores de Ca e P foram levemente maiores que os obtidos por Ghisi et al. (1994) em iguais freqüências de corte (IEC de 35 dias e 49 dias).

Os teores de $\mathrm{Ca}$ inseriram-se à faixa de variação citada por Machin (1977), e a média deles foi semelhante ao valor mínimo da faixa citada por Squibb et al. (1954) para plantas de 12 a $84 \mathrm{~cm}$ de altura, e consideravelmente menor que o obtido por Duarte, Sgarbieri e Benatti Júnior (1997)Os teores de $P$ aproximaram-se ao limite máximo da faixa de variação citada por MACHIN (1977); foram maiores que o obtido por Duarte, Sgarbieri e Benatti Júnior (1997)e alocaram-se à média da faixa de variação citada por Squibb et al. (1954) para plantas de 12 a $84 \mathrm{~cm}$ de altura.

As diferenças entre o presente trabalho e a literatura consultada nos resultados das variáveis estudadas no rami podem ser atribuídas à textura, estrutura e riqueza mineral do solo; adaptação da planta às condições climáticas da região; idade fisiológica, potencial genético da espécie e cultivar e componente estudado da planta. 
BIANCHINI, D. et al. Teores de alguns nutrientes do Rami (Boehmeria nívea CV Myasaki) sob duas fontes de adubo nitrogenado e quatro freqüências de corte. PUBVET, Londrina, V. 6, N. 13, Ed. 200, Art. 1341, 2012.

O efeito semelhante entre o sulfato de amônio e a cama de frango, como fontes de $\mathrm{N}$ nos resultados quanto à concentração de nutrientes no rami, reveste-se de grande importância, podendo a demanda por nitrogênio ser atendida pelo esterco produzido na própria propriedade.

Pelo substancial aumento na demanda produtiva de grãos alimentícios e biocombustiveis, seria preciso avançar sobre a área da pecuária, cujo aumento da produção de carne e leite poderia ser atendido pela combinação de conhecimentos com aplicação correta de técnicas que resultam em altos índices de lotação e desempenho animal; ou pelo confinamento e semiconfinamento, que constituem ferramentas de terminação rápida de animais e de redução de emissão de gases com monumental produção de esterco.

\section{CONCLUSÕES}

O nitrogênio mineral pode plenamente ser substituído pelo resíduo de limpeza de piso aviário, fonte de nitrogênio orgânico, nas variáveis qualitativas estudadas na forragem de rami.

O Intervalo entre corte (IEC) mais promissor foi o de 42 dias.

\section{BIBLIOGRAFIA}

ALVES, A.J.R., PACHECO, B.M., ALENCAR, J.A. Avaliação do rami (Boehmeria nivea, Gaud.) submetido a diferentes freqüências de corte. In: REUNIÃO ANUAL DA SOCIEDADE BRASILEIRA DE ZOOTECNIA, 34, 1997. Juiz de Fora. Anais...Juiz de Fora, Sociedade Brasileira de Zootecnia, 1997, p.228-9.

BUFARAH, G., GHISI, O.M.A.A., CAIELLI, E.L. et al. O potencial da cultura do rami como planta forrageira. Zootecnia, Nova Odessa, SP, v.24, n.4, p.419-32, 1986.

DUARTE, A. de A., SGARBIERI, V.C., BENATTI JÚNIOR, R. Composição e valor nutritivo da farinha de folhas de rami para animais monogástricos. Rev. agropec. bras., Brasília, v.32, n.12, p.1295-1302, 1997.

ECHEVERRY, H.S. El ramio como forrage. Agric. Trop., Bogotá, v.16, n.11, p.740-3, 1960.

FARIAS, I., FERNANDES, A. P.M., LIRA, M.A. et al. Efeito da adubação orgânica sobre a produção de forragem de milho, sorgo e capim elefante. In: REUNIÃ̃O ANUAL DA SOCIEDADE BRASILEIRA DE ZOOTECNIA, 18, 1981. Goiânia. Anais...Goiânia, Sociedade Brasileira de Zootecnia, 1981, p.44. 
GHISI, O.M.A.A., FERRARI JÚNIOR, E., BUFARAH, G. et al. Efeito das freqüências de corte no rami (Boehmeria nívea cv. Myasaki) sobre a produção, composição e digestibilidade "in vitro" da matéria seca. B. Indústr. anim., Nova Odessa, v. 51, n.2, p.111-8, 1994.

MACHIN, D.H. Ramie as an animal feed: a review. Trop. Sci., v.19, n.4, p. 187-95, 1977.

MEDINA, J.C. Instruções para a cultura do rami em São Paulo. Campinas, SP: Instituto Agronômico de Campinas, 1963. 20 p. (Boletim Técnico, 64).

OLIVEIRA, A.L. Composição química do rami (Boehmeria nívea, Gaud) submetido à adubação orgânica e a diferentes intervalos de cortes. Revista da FZVA, Uruguaiana, v.14, n.1,p.53-68, 2007.

OLIVO, C.J., LOVATO, T., MORCELLI, T.B. et al. Utilização de cama de bovinos e de adubação mineral em mistura de aveia e azevém sobre a produção de leite. In: REUNIÃO ANUAL DA SOCIEDADE BRASILEIRA DE ZOOTECNIA, 24, 1987. Brasília. Anais...Brasília, Sociedade Brasileira de Zootecnia, 1987, p.162.

PRIMAVESI, A. Manejo ecológico de pastagens: em regiões tropicais e subtropicais. Porto Alegre, Centaurus, 1982. 180 p.

RODRIGUEZ, N.M., VELOSO, C.M., MOURÃO, G.B. et al. Degradabilidade ruminal da proteína de folíolos de leucena, guandu e soja perene e de folhas de rami e mandioca. In: REUNIÃO ANUAL DA SOCIEDADE BRASILEIRA DE ZOOTECNIA, 33, 1996. Brasília. Anais...Brasília, Sociedade Brasileira de Zootecnia, 1996, p.301.

SANTOS, L. E., CUNHA, W., RODA, D.S. et al. Produção de leite em caprinos alimentados com níveis crescentes de rami (Boehmeria nivea, Gaud.). B. Indústr. anim., Nova Odessa, v. 52, n.2, p.153-9, 1995.

SANTOS, L. E., DUPAS, W., LEMOS NETO, M.J. et al. Resíduo da desfibragem do rami (Boehmeria nivea, Gaud.) na alimentação de caprinos. B. Indústr. anim., Nova Odessa, v. 47, n.1, p.73-80, 1990.

SCHNEIDER, B.H., LUCAS, H.L. Estimation of the digestibility for feed in which there are only proximate composition. J. Anim. Sci., v. 10, n.706, 1951.

SILVA, J.H.V., CAMPOS, J., RODRIGUES, M.T. et al. Desempenho de cabras alimentadas com excesso de oferta de fenos. In: REUNIÃO ANUAL DA SOCIEDADE BRASILEIRA DE ZOOTECNIA, 33, 1996. Fortaleza. Anais...Fortaleza, Sociedade Brasileira de Zootecnia, 1996, p.208.

SPOLADORE, D.S., BENATTI JÚNIOR, R., TEIXEIRA, J.P.F. et al. Composição química das folhas e dimensões das fibras lenhosas em rami. Bragantia, Campinas, v. 43, n.1, p.229-36, 1984.

SQUIBB, R.L., MENDEZ, J., GUZMAN, M.A. et al. Ramie a high protein forage crop for tropical areas. J. Brit. Grassld. Soc. Maidenhead, Berks v.9, n.4, p.313-23, 1954.

WERNER, J.C. Adubação de pastagens. Nova Odessa, SP: Instituto de Zootecnia, 1986. 49 p. (Boletim Técnico, 18). 